\title{
Complete genome sequence analysis of human echovirus 30 isolated during a large outbreak in Guangdong Province of China, in 2012
}

\author{
Hong Xiao $\cdot$ Keyong Huang $\cdot$ Ling Li $\cdot$ \\ Xianbo Wu $\cdot$ Li Zheng $\cdot$ Chengsong Wan • \\ Wei Zhao $\cdot$ Changwen Ke $\cdot$ Bao Zhang
}

Received: 2 June 2013/Accepted: 3 July 2013/Published online: 29 August 2013

(c) The Author(s) 2013. This article is published with open access at Springerlink.com

\begin{abstract}
In May and June 2012, an outbreak of aseptic meningitis caused by Echovirus 30 (E30) occurred on a large scale in Luoding, Guangdong Province, China. Our team successfully isolated one subtype, strain 2012EM161, and its complete genome was sequenced. The phylogenetic tree of viral protein (VP) 1 gene sequences showed that the viral isolate was similar to the E30 strain prevalent in Fujian (2011), with identity of $98.05-99.32 \%$ and 98.63-99.32 \% for nucleotides and amino acids respectively. Whole genome-based phylogenetic analysis indicated that 2012EM161 contained the most proximate consensus to DQ246620 (Zhejiang, 2003) and FDJS03 (AY948442, Jiangsu, 2005), with nucleotide homogeneity of $87.09 \%$ and $86.98 \%$ respectively. The RDP4.16 and Simplot analysis showed that the newly discovered 2012EM161 was probably a recombinant, which was closely related to the strain of E30 (DQ246620) in the first half of the genome and the strain of E6 (JX976771) in genomic P3 region. The whole genome sequence of 2012EM161
\end{abstract}

H. Xiao, K. Huang and L. Li contributed equally to this work.

Electronic supplementary material The online version of this article (doi:10.1007/s00705-013-1818-0) contains supplementary material, which is available to authorized users.

H. Xiao · C. Ke $(\bowtie)$

Institute of Microbiology, Center for Diseases Control and Prevention of Guangdong Province, 176 Xin Gang West Road, Guangzhou, Guangdong 510300, People's Republic of China e-mail: kecw1965@qq.com

K. Huang $\cdot$ L. Li $\cdot$ X. Wu $\cdot$ L. Zheng $\cdot$ C. Wan $\cdot$ W. Zhao ·

B. Zhang $(\bowtie)$

Lab of Biosafety Level 3, Southern Medical University,

Guangzhou 510515, People's Republic of China

e-mail: zhang20051005@126.com will allow further study of the origin, evolution, and the molecular epidemiology of E30 strains.

\section{Introduction}

Echovirus 30 (E30), with an ssRNA positive-stranded genome, is a member of the genus Enterovirus in the family Picornaviridae and belongs to human enterovirus subgroup B (HEV-B) [7]. It is a major pathogen associated with aseptic meningitis, which has occurred at high prevalence in recent decades all over the world, including America [13], Canada [4], France [12], Italy [5], Germany [15], England [2], Japan [8], Korea [9], India [11], Taiwan $[3,10]$, and the Chinese Mainland. In China, several E30 epidemics have been recorded, in Jiangsu [18], Shandong [16], Fujian [17] and other provinces. In 2012, an epidemic of E30 virus infection that involved 183 children occurred in Luoding, Guangdong province, and this was the first E30 epidemic reported in Guangdong Province. We successfully isolated a virus strain from one of the patients which was identified as E30 by complete genome sequencing.

\section{Provenance of the virus materials}

The strain 2012EM161 was isolated from the cerebrospinal fluid (CSF) of a female infant who suffered aseptic meningitis during the epidemic in Luoding, Guangdong Province. This female infant recovered after one week of symptomatic treatment. The isolated strain was identified as E30 by immunological detection, fluorescence quantitative PCR and sequencing of the VP1 region.

Human rhabdomyosarcoma (RD) cell line was used for expansion and passage of the 2012EM161 strain. RD cell 
line firstly established by McAllister et al. [14] is useful for the diagnosis of most of the important enterovirus infections [1]. Cells were cultured in DMEM (Dulbecco's Modified Eagle's Medium) containing $10 \%$ fetal bovine serum (FBS) in a humidified incubator at $37{ }^{\circ} \mathrm{C}$ with $5 \% \mathrm{CO}_{2}$. The RNA was extracted using a viral extraction kit (Qiagen), and its 3' end was amplified and sequenced using a 3'-full RACE core set (Takara, Cat:6106). Primers were designed according to conserved sequences in the whole genome sequences of fourteen strains of E30 reported in Genbank and were used to determine the 5' and internal viral sequences using an RNA PCR kit ver3.0 (TaKaRa, Cat:Drr019A). The primers used are listed in Supplementary Table 1.

Sanger sequencing was applied on an AB3730 DNA analyzer, and sequence assembly was performed with
DNASTAR7.0 software. The tree was constructed with MEGA 5.1 software using the neighbor-joining method with 1,000 bootstrap replicates. The VP1 sequence and whole genome sequence are listed in Supplementary Table 2 and Table 3 respectively. RDP4.16 and simplot3.5.1 were used to analyze the recombinant sequences of several strains of HEV-B (Supplementary Table 3).

\section{Sequence properties}

The full-length genome of 2012EM161 comprised 7427 bp and included a 741 bp $5^{\prime}$ UTR, a 101 bp $3^{\prime}$ UTR and an open reading frame encoding a 2194 amino acid polyprotein, the cleavage site of which was consistent with
Fig. 1 Phylogenetic trees construction with VP1 protein and complete genome of Echovirus E30. A VP1 protein with 876 bp of 246 strains Echovirus E30; B genome sequence (nt94-7367) of some Human entervirus B protype and SVDV genome for reference. The nucleotide position is based on the E30 of 2012EM161 stain. The trees were built with $\mathrm{NJ}$ method using MEGA 5.1 software and tested with 1000 bootstrap replicates

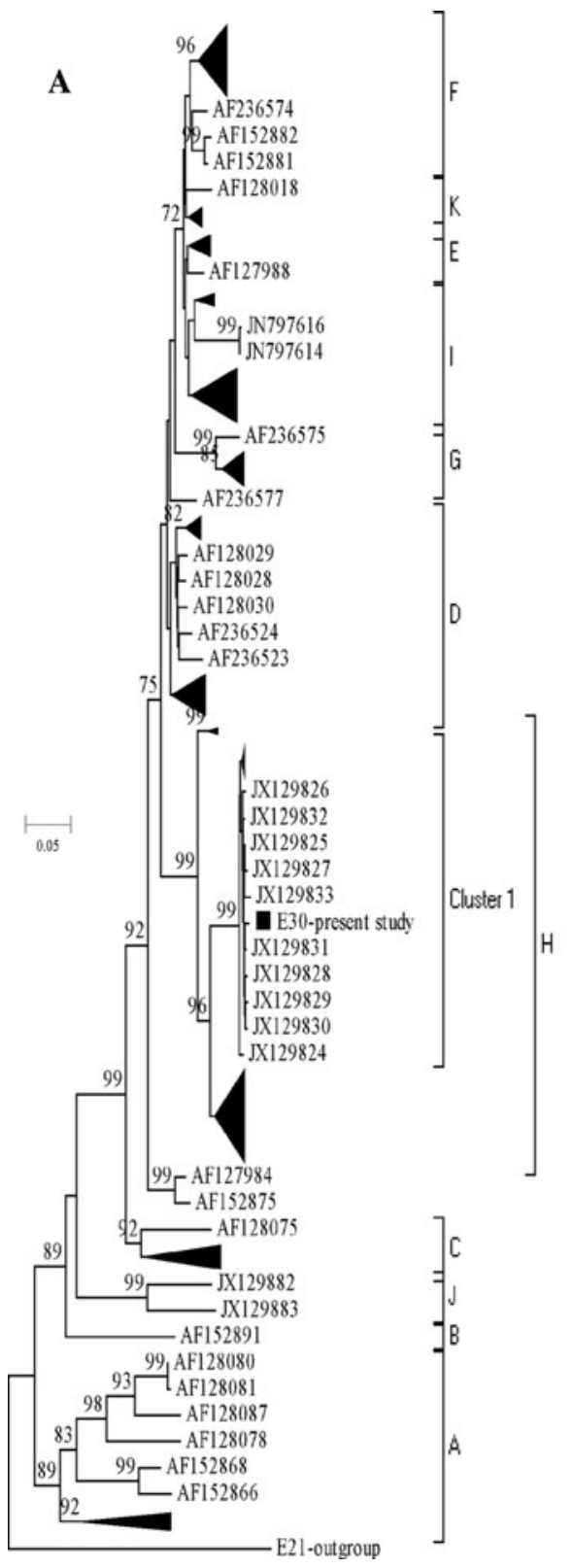


JX854435 [6]. The phylogenetic tree based on the VP1 region showed that 2012EM161 was located in the cluster 1 of h lineage of E30 (Fig. 1A), with similarity values of $98.63 \%$ to $99.32 \%$. The cluster 1 , including the isolates from JX129810 to JX129833, together other isolates caused 284 cases diagnosed with aseptic meningitis in Fujian Province of China from April to June in 2011 [17]. In addition, the VP1 gene's nucleotide/amino acid homology values of the 2012EM161 strain with DQ246620 and FDJS03 (Genbank NO. AY948442) were $98.23 \%$ I
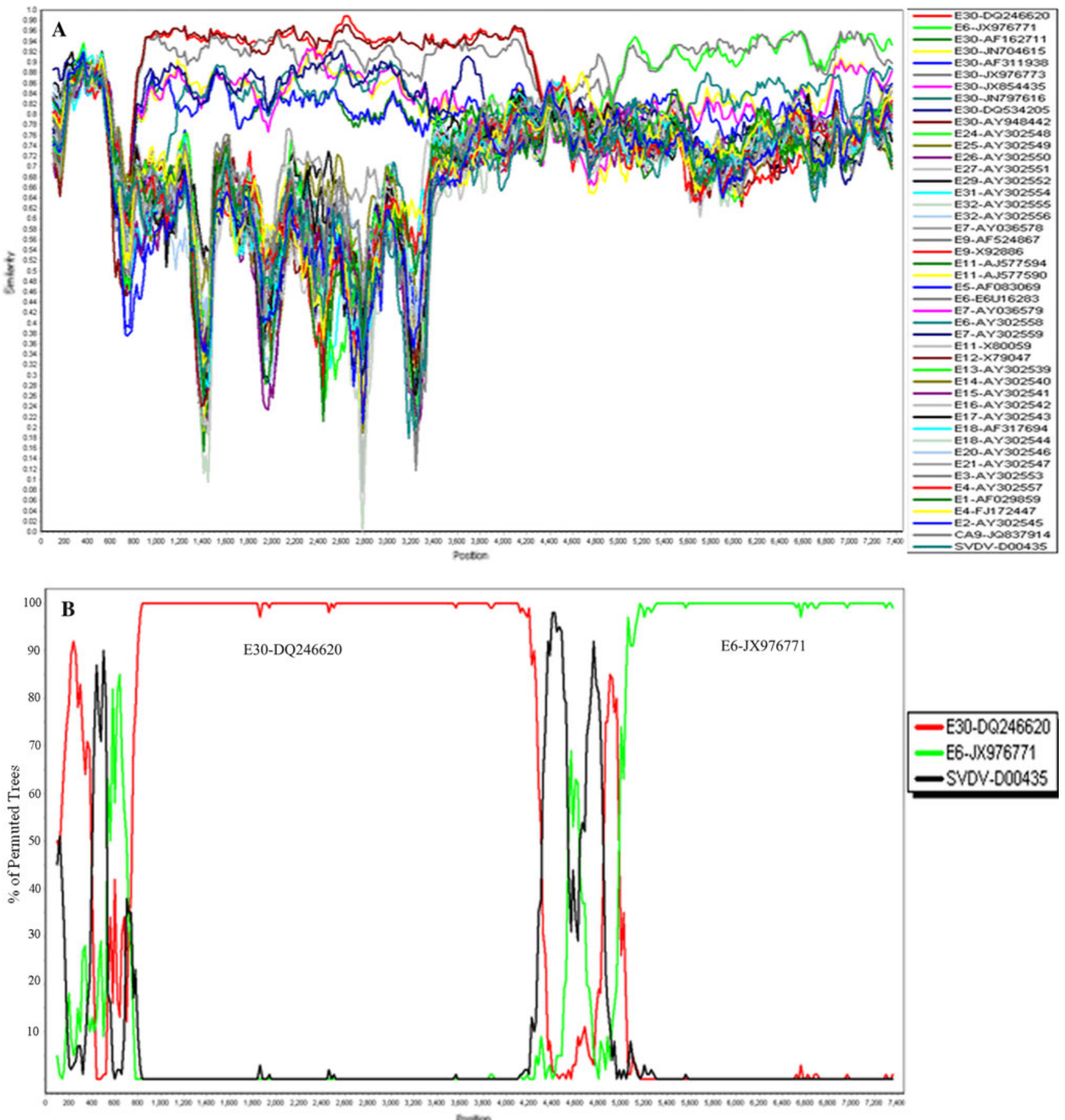

Fig. 2 Similarity and bootscanning analysis of 2012 EM161 Echovirus E30 strain. A similarity plot analysis with other human entervirus B strains and SVDV for reference. B bootscanning result on the putative recombinant 2012EM161 strain and its parental sequences. The parameters are used as window size $200 \mathrm{bp}, 20 \mathrm{bp}$ step size, distance model of kirmura 2-parameter, NJ tree model, 100 pseudoreplicates. The arbitary recombinant threshold is $70 \%$ 
$98.28 \%$ and $94.29 \% / 98.29 \%$ respectively. Strain of DQ246620 caused outbreak of aseptic meningitis in Zhejiang Province of China in 2003, while FDJS03 strain emerged outbreak in Jiangsu Province of China [19]. The above results proved that our isolated strain, 2012EM161, belonged to E30 type.

Complete genomic sequence (CGS) alignment in Genbank revealed that 2012EM161 had a high similarity to E30 strains from provinces of Zhejiang (DQ246620) and Jiangsu (AY948442), with the identity of $87.09 \%$ and $86.98 \%$ respectively. Phylogenetic analysis further demonstrated that 2012EM161 and the E30 strain of DQ246620 and AY948442 belonged to the same series (Fig. 1B). However, the score of individual VP1 gene alignment was higher than that of CGS, $98.23 \% / 98.28 \%$ vs $87.09 \%$ / $86.98 \%$ in DQ246620 and AY948442, which indicated that recombination had probably occurred in the 2012EM16 strain. The results of the RDP4.16 and simplot3.5.1 analysis showed that 2012EM161 had similarity of $75 \%-85 \%$ at the 5' end and non-structural protein region within HEV B strains (Fig. 2A). Based on the current nucleotide dataset, Bootscan program analysis suggested that the isolated strain was a mosaic reassortant, which manifested the highest similarity to the strain of E30 from Zhejiang (DQ246620) in the 5' half of the genome and the strain of E6 strain (JX976771) in the P3 region, with the potential initial recombination site at 4907 bp (Fig. 2B)."

Given that a whole genome sequence for the E30 strain responsible for the meningitis epidemic in Fujian (2011) [17] is unavailable, it is difficult to evaluate its homogeneity with the 2012EM161 strain of Guangdong (2012), or to determine whether 2012EM161 originated from Fujian. This will only be clarified when the whole genome sequence of the Fujian strain is obtained. This is the first report of the whole genome sequence of the E30 strain prevalent in Luoding (May to June, 2012), and it will contribute to further study of the molecular epidemiology, source, and evolution of E30 strains.

The complete genomic sequence of E30 2012EM161 strain was deposited in the Genbank database under accession no. KC897073.

Acknowledgment This study was funded by grants from the Natural Science Foundation of China (NO. 30600733 and NO.81272483) and Guangdong Provincial Science and Technology (NO. 2010A040302003 and NO. 2011B031800163).

\section{Conflict of interest No conflict of interest.}

Open Access This article is distributed under the terms of the Creative Commons Attribution License which permits any use, distribution, and reproduction in any medium, provided the original author(s) and the source are credited.

\section{References}

1. Bell EJ, Cosgrove BP (1980) Routine enterovirus diagnosis in a human rhabdomyosarcoma cell line. Bull World Health Organ 58:423-428

2. Carrol ED, Beadsworth MB, Jenkins N, Ratcliffe L, Ashton I, Crowley B, Nye FJ, Beeching NJ (2006) Clinical and diagnostic findings of an echovirus meningitis outbreak in the north west of England. Postgrad Med J 82:60-64

3. Chen GW, Huang JH, Lo YL, Tsao KC, Chang SC (2007) Mosaic genome structure of echovirus type 30 that circulated in Taiwan in 2001. Arch Virol 152:1807-1817

4. Drebot MA, Nguan CY, Campbell JJ, Lee SH, Forward KR (1994) Molecular epidemiology of enterovirus outbreaks in Canada during 1991-1992: identification of echovirus 30 and coxsackievirus B1 strains by amplicon sequencing. J Med Virol 44:340-347

5. Faustini A, Fano V, Muscillo M, Zaniratti S, La Rosa G, Tribuzi L, Perucci CA (2006) An outbreak of aseptic meningitis due to echovirus 30 associated with attending school and swimming in pools. Int J Infect Dis 10:291-297

6. Han JF, Xu LJ, Cao RY, Zhao H, Jiang T, Deng YQ, Li YX, Zhu SY, Yu M, Qin ED, Qin CF (2012) Complete genome sequence analysis of human echovirus type 30 isolated in China. J Virol 86:13856-13857

7. Harford CG, Middelkamp JN, Fox J, Reed CA (1970) Human diploid cell cutures in diagnosis of echovirus 30 meningitis. Arch Intern Med 125:864-866

8. Iwai M, Horimoto E, Obara M, Obuchi M, Kurata T, Kawagoshi K, Nakamura S, Shimizu H, Yoshida H, Takizawa T (2011) Endemic transmission of echovirus 30 in Toyama, Japan in 2010 is verified by environmental surveillance. Jpn J Infect Dis 64:165-167

9. Jeong EJ, Lee JH, Kim MS, Bae GR, Jung C, Lee K, Choi SM, Kim DK, Lee DS, Kim WD, Jee YM, Cheong HK, Lee SH (2010) Molecular characterization of enteroviruses detected in Gyeong$\mathrm{Ju}$ and Po-Hang provinces of Korea in 2003. Arch Virol 155:1707-1712

10. Ke GM, Lin KH, Lu PL, Tung YC, Wang CF, Ke LY, Lee MS, Lin PC, Su HJ, Lin YY, Huang TP, Wang JR, Wang SY, Hsu LC, Chu PY (2011) Molecular epidemiology of Echovirus 30 in Taiwan, 1988-2008. Virus Genes 42:178-188

11. Kumar A, Shukla D, Kumar R, Idris MZ, Jauhari P, Srivastava S, Dhole TN (2013) Molecular identification of enteroviruses associated with aseptic meningitis in children from India. Arch Virol 158:211-215

12. Leveque N, Jacques J, Renois F, Antona D, Abely M, Chomel JJ, Andreoletti L (2010) Phylogenetic analysis of Echovirus 30 isolated during the 2005 outbreak in France reveals existence of multiple lineages and suggests frequent recombination events. J Clin Virol 48:137-141

13. Likosky WH, Emmons RW, Davis LE, Thompson RS (1972) U.S. cases in 1968: epidemiology of echovirus 30 aseptic meningitis. Health Serv Rep 87:638-642

14. McAllister RM, Melnyk J, Finkelstein JZ, Adams EJ, Gardner MB (1969) Cultivation in vitro of cells derived from a human rhabdomyosarcoma. Cancer 24:520-526

15. Roth B, Enders M, Arents A, Pfitzner A, Terletskaia-Ladwig E (2007) Epidemiologic aspects and laboratory features of enterovirus infections in Western Germany, 2000-2005. J Med Virol 79:956-962

16. Yang J, Zhang XL, Tao ZX, Wang HY, Lin XJ, Ji SX, Liu Y, Zhang YJ, Xu AQ (2011) Genetic analysis of echovirus 30 isolated from acute meningitis/encephalitis syndrome cases in Linyi 
city of Shandong province, China. Zhonghua Shi Yan He Lin Chuang Bing Du Xue Za Zhi 25:409-412

17. Yang XH, Yan YS, Weng YW, He AH, Zhang HR, Chen W, Zhou Y (2013) Molecular epidemiology of Echovirus 30 in Fujian, China between 2001 and 2011. J Med Virol 85:696-702

18. Zhao YN, Jiang QW, Jiang RJ, Chen L, Perlin DS (2005) Echovirus 30, Jiangsu Province, China. Emerg Infect Dis $11: 562-567$
19. Zhao YN, Perlin DS, Park S, Jiang RJ, Chen L, Chen Y, Gardiner R, Jiang QW (2006) FDJS03 isolates causing an outbreak of aseptic meningitis in China that evolved from a distinct Echovirus 30 lineage imported from countries of the Commonwealth of Independent States. J Clin Microbiol 44:4142-4148 